\title{
OURNAL OF
}

MANAGED

CARE \& SPECIALTY

HARMACY

Supplement $\square$ Volume 22 n Number 10-a $₫$ October 2016

\section{Primary Biliary Cholangitis: Medical and Specialty Pharmacy Management Update}

Christopher L. Bowlus, MD; James T. Kenney, RPh, MBA;

Gary Rice, RPh, MS, MBA, CSP; and Robert Navarro, PharmD 


\section{JMCP}

\section{Publisher}

Susan A. Cantrell, RPh, CAE

Chief Executive Officer

Academy of Managed Care Pharmacy

\section{Editor-in-Chief}

Laura E. Happe, PharmD, MPH

727.488.2700, lhappe@jmcp.org

\section{Assistant Editor}

Robert P. Navarro, PharmD

University of Florida College of Pharmacy

Gainesville, FL

\section{Assistant Editor}

Karen L. Rascati, PhD

University of Texas College of Pharmacy

Austin, TX

\section{Assistant Editor}

Karen M. Stockl, PharmD

OptumRx, Irvine, CA

\section{Managing Editor}

Jennifer A. Booker

703.317.0725, jmcpreview@amcp.org

\section{Production Editor}

Carol Blumentritt

602.616.7249, cblumentritt@amcp.org

\section{Graphic Designer}

Margie C. Hunter

703.297.9319, mhunter@amcp.org

\section{Account Manager}

Grant Menard, American Medical Communications, Inc 267.614.6809, GMenard@americanmedicalcomm.com

This supplement to the Journal of Managed Care \& Specialty Pharmacy (ISSN 1944-706X) is a publication of the Academy of Managed Care Pharmacy, 100 North Pitt St., Suite 400, Alexandria, VA 22314; 703.683.8416; 703.683 .8417 (fax).

Copyright $(\odot$ 2016, Academy of Managed Care Pharmacy. All rights reserved. No part of this publication may be reproduced or transmitted in any form or by any means, electronic or mechanical, without written permission from the Academy of Managed Care Pharmacy.

POSTMASTER: Send address changes to JMCP,

100 North Pitt St., Suite 400, Alexandria, VA 22314.

\section{Supplement Policy Statement}

\section{Standards for Supplements to the}

Journal of Managed Care \& Specialty Pharmacy Supplements to the Journal of Managed Care \& Specialty Pharmacy (JMCP) are intended to support medical education and research in areas of clinical practice, health care quality improvement, or efficient administration and delivery of health benefits. The following standards are applied to all JMCP supplements to ensure quality and assist readers in evaluating potential bias and determining alternate explanations for findings and results

1. Disclose the principal sources of funding in a manner that permits easy recognition by the reader.

2. Disclose the existence of all potential conflicts of interest among supplement contributors, including financial or personal bias. 3. Describe all drugs by generic name unless the use of the brand name is necessary to reduce the opportunity for confusion among readers.

4. Identify any off-label (unapproved) use by drug name and specific off-label indication.

5. Strive to report subjects of current interest to managed care pharmacists and other managed care professionals.

6 . Seek and publish content that does not duplicate content in the Journal of Managed Care \& Specialty Pharmacy.

7. Subject all supplements to expert peer review.
Christopher L. Bowlus, MD, is Chief and Professor of Medicine in Gastroenterology and Hepatology at the University of California, Davis, Medical Center. He specializes in liver diseases, specifically immunologic diseases of the liver, including primary biliary cirrhosis, primary sclerosing cholangitis, and autoimmune hepatitis. Bowlus is interested in elucidating the underlying genetic and immunologic causes of autoimmune diseases and using this information to develop more effective treatments for primary biliary cirrhosis, primary sclerosing cholangitis, and autoimmune hepatitis. Bowlus received his medical degree from the St. Louis University School of Medicine; completed his internship and residency at the University of California, Davis, Medical Center; and completed a fellowship at the Yale University School of Medicine.

James T. Kenney, RPh, MBA, is Manager, Specialty and Pharmacy Contracts at Harvard Pilgrim Health Care (HPHC), which is a full-service health benefits company in Wellesley, Massachusetts. HPHC serves more than 1.3 million commercial and Medicare members and also operates exchange products in Massachusetts, Maine, and New Hampshire. HPHC manages multiple formulary designs, including open and closed formats, and administers all pharmacy benefit programs internally. Kenney has been with HPHC for more than 35 years and has held several positions, including Staff Pharmacist, Chief Pharmacist, Assistant Administrator for Pharmacy Programs, and Pharmacy Operations Manager. Currently, Kenney has corporate responsibility for the pharmacy contracts program with pharmaceutical manufacturers and specialty pharmacy providers in support of a budget of more than $\$ 700$ million. Kenney is also a voting member of the Pharmacy and Therapeutics Committee for HPHC. His accomplishments include creating and managing the network pharmacy program for the group practice model of HPHC, developing the pharmacy rebate program, creating the Medicare Part D contracting program, and coleading the Pharmacy Materials Management System project. Kenney developed the specialty pharmacy program at HPHC for injectables as well as a second program in support of infertility management. Kenney is a pharmacy preceptor for the Massachusetts College of Pharmacy and Allied Health Sciences and currently serves on the Massachusetts Pharmacists' Association Government and Legislative Affairs Committee. He is also an active member of the Academy of Managed Care Pharmacy (AMCP) and has served on its Nomination Committee, Grassroots Advocacy Committee, Legislative and Regulatory Action Committee, Legislative Committee, Public Policy Committee, and Format Executive Commitee. He has served as a peer reviewer for the Journal of Managed Care E Specialty Pharmacy and is currently a member of AMCP's board of directors.

Gary Rice, RPh, MS, MBA, CSP, is the Senior Vice President of Clinical, Education, and Human Resources Services at Diplomat Pharmacy in Flint, Michigan, where he provides leadership, strategy, and planning for all clinical, education, and human resources functions. He works closely with operations, IT, business development, sales and marketing; managed markets for tactical positioning and clinical service support from development through implementation; and oversees clinical initiatives and services. Rice is also the immediate past president and a current board member of the Specialty Pharmacy Certification Board and a member of the Center for Pharmacy Practice Accreditation Specialty Pharmacy Practice Standards Development Committee. Rice has more than 30 years of pharmacy experience in pharmacy benefits management, managed markets, home infusion, durable medical equipment, retail, and hospital pharmacy. He earned his bachelor of science in pharmacy from the Massachusetts College of Pharmacy and Allied Health Sciences in Boston. He received a master of science in pharmacy from the University of Houston and completed a pharmacy residency program accredited by the American Society of Health-System Pharmacists at the Veterans Administration Medical Center in Houston. Rice earned his master's degree in business administration from the University of Phoenix and obtained his specialty pharmacy certification in October 2013.

Robert Navarro, PharmD, is cofounder and first president of Academy of Managed Care Pharmacy and the Foundation for Managed Care Pharmacy (FMCP). Navarro is a recognized authority within the managed care industry and was the 2009 recipient of the FMCP Stephen G. Avey Award for his contributions to managed pharmacy practice. Navarro is Clinical Professor in the Department of Pharmaceutical Outcomes and Policy at the University of Florida College of Pharmacy, where he teaches "Regulating Pharmaceutical Access and Cost" and other courses in the online master of science in pharmacy program. He is editor of the textbook Managed Care Pharmacy Practice, 2nd ed., and coauthor of the managed care pharmacy benefit chapter in the ASHP Handbook of Institutional Pharmacy Practice, 4th ed., and the pharmacy benefit chapter in Essentials of Managed Health Care, 6th ed. He is also an assistant editor with the Journal of Managed Care $\&$ Specialty Pharmacy. 


\section{Table of Contents}

\section{Primary Biliary Cholangitis: Medical and Specialty Pharmacy Management Update}

Christopher L. Bowlus, MD; James T. Kenney, RPh, MBA; Gary Rice, RPh, MS, MBA, CSP; and Robert Navarro, PharmD

\section{S3 Abstract}

S4 Primary Biliary Cholangitis, Current Clinical Management, Unmet Need, and Potential New Therapies on the Horizon

S8 Managing New Drug Therapies for PBC within a Health Plan Pharmacy Benefit

S11 Role of Specialty Pharmacy in PBC Drug Distribution, Patient Management, and Outcomes Management

\section{S12 Conclusions}

S12 References

S14 Continuing Education

Learning Objectives

- Describe the pathophysiology, clinical course, diagnostic process, and burden of primary biliary cholangitis (PBC).

- Discuss current medical and pharmacotherapy management of PBC.

- Describe the potential clinical and patient care benefits of new drugs in development for treatment of PBC.

- Discuss new drugs and their place in the overall management of patients with PBC.

- Discuss patient management, patient education, dosage titration, and adverse event monitoring for specialty pharmacists with regard to PBC.

Forum

This article summarizes the presentations and discussions from an educational symposium that was conducted at the Academy of Managed Care Pharmacy Nexus 2015 conference in Orlando, Florida, on October 28, 2015.

\section{Funding}

There is no fee for this activity, as it is sponsored through an independent educational grant from Intercept Pharmaceuticals.

\section{Acknowledgments}

The authors thank the staff of Analysis Group for coordinating the symposium program and assisting with preparation of this summary.

Release Date: October 3, 2016 Expiration Date: October 3, 2017 
Pharmacist Accreditation Statement

The University of Florida College of Pharmacy is accredited by the Accreditation Council for Pharmacy Education as a provider of continuing pharmacy education.

\section{Credit Designation}

The University of Florida College of Pharmacy designates this continuing education activity for 2.0 contact hours (0.2 CEUs) of the Accreditation Council for Pharmacy Education. The Universal Activity Number for this program is $0012-$ 9999-16-375-H01-P. Type of activity: Knowledge.

\section{Credit Instructions}

In order to receive continuing education (CE) credit for this program, you must complete the following:

1. Read the entire supplement.

2. Complete the online posttest at http://cpe.pharmacy.ufl.edu/pbcquiz/. To receive credit, you must achieve a score of $70 \%$.

3. Complete the online program evaluation form following the posttest.

The University of Florida College of Pharmacy will report CPE credit to the CPE monitor within 30 days following the activity. For pharmacists registered in Florida, credit will also be reported to the CE broker.

\section{Disclosure of Conflicts of Interest}

The University of Florida College of Pharmacy requires instructors, planners, managers, and other individuals who are in a position to control the content of this activity to disclose any real or apparent conflict of interest (COI) they may have as related to the content of this activity. All identified COIs are thoroughly vetted and resolved according to University of Florida policy. The existence or absence of COI for everyone in a position to control content will be disclosed to participants prior to the start of each activity.

\section{Privacy Policy}

The University of Florida privacy policy is available here: http://privacy.ufl.edu/privacy-policies-andprocedures/informationprivacy-statement/.

\section{Author Correspondence Information}

Christopher L. Bowlus, MD

Chief and Professor of Medicine

Division of Gastroenterology and Hepatology

University of California, Davis, Medical Center

4150 V St., Ste. 3100

Sacramento, CA 95817

916.734.2812

clbowlus@ucdavis.edu

James T. Kenney, RPh, MBA

Manager, Specialty and Pharmacy Contracts

Harvard Pilgrim Health Care (Wellesley, MA)

93 Worcester St.

Wellesley, MA 02481

617.460.2325

jim_kenney@hphc.org

Gary Rice, RPh, MS, MBA, CSP

Senior Vice President, Clinical, Education, and Human Resources Services

Diplomat Pharmacy

4100 S. Saginaw St.

Flint, MI 48507

810.768 .9863

grice@diplomat.is

\section{Robert Navarro, PharmD}

Clinical Professor

University of Florida College of Pharmacy

8218 N.W. 44th Dr.

Gainesville, FL 32653

919.621 .0024

robert@navarropharma.com 


\title{
Primary Biliary Cholangitis: Medical and Specialty Pharmacy Management Update
}

\author{
Christopher L. Bowlus, MD; James T. Kenney, RPh, MBA;
}

Gary Rice, RPh, MS, MBA, CSP; and Robert Navarro, PharmD

\section{ABSTRACT}

BACKGROUND: Chronic liver disease and cirrhosis are a leading cause of morbidity and mortality in the United States. Primary biliary cholangitis (PBC), previously known as primary biliary cirrhosis and which has been designated an orphan condition, is a chronic autoimmune disease resulting in the destruction of the small bile ducts in the liver. Without effective treatment, disease progression frequently leads to liver failure and death. Until May 2016, the only FDA-approved treatment for PBC was ursodiol (UDCA), an oral hydrophilic bile acid, which can slow progression of liver damage due to PBC. However, 1 out of 3 patients taking UDCA has an inadequate biochemical response, leading to increased risk of disease progression, liver transplantation, and mortality. Given this unmet clinical need, new therapies are in development for the treatment of PBC. To provide pharmacists with an overview of the latest research on the pathophysiology of PBC and potential new treatment options and to highlight medical and specialty pharmacy approaches to managing access to drugs to treat orphan diseases such as PBC, a 2-hour satellite symposium was presented in conjunction with the 2015 Academy of Managed Care Pharmacy (AMCP) Nexus meeting. Although obeticholic acid was approved by the FDA for the treatment of PBC in May 2016, this development occurred after the symposium presentation. The symposium was supported by an independent educational grant from Intercept Pharmaceuticals and was managed by Analysis Group. Robert Navarro, PharmD, moderated the CPE-accredited symposium titled "Medical and Specialty Pharmacy Management Update on Primary Biliary Cirrhosis." Expert panelists included Christopher L. Bowlus, MD; James T. Kenney, RPh, MBA; and Gary Rice, RPh, MS, MBA, CSP.

OBJECTIVE: To summarize the educational satellite symposium presentations and discussions.

SUMMARY: Autoimmune liver diseases, including PBC, are responsible for $15 \%$ of all liver transplants performed and an equal percentage of deaths related to liver disease. UDCA is the only FDA-approved therapy for treatment of $\mathrm{PBC}$ and is considered the standard of care. Nevertheless, many patients do not respond to UDCA, creating the need for new therapeutic options to improve clinical outcomes for PBC patients with inadequate response to treatment. While several agents are being studied in combination with UDCA, monotherapy with the novel agent obeticholic acid, a farnesoid $\mathrm{X}$ receptor agonist, has also shown promising results.

Health plans are anticipated to assign any newly introduced therapy for the treatment of PBC to specialty pharmacy given its orphan disease status. This assignment enables the health plan to receive disease education, which is particularly important when new drugs are indicated for orphan diseases, and assistance with designing appropriate prior authorization criteria. The clinical value of any new therapeutic options that will inform formulary decisions and prior authorization criteria will be assessed based on evidence of efficacy, safety, and tolerability, among other factors, such as the potential to reduce or delay medical resource utilization (e.g., liver transplant). Key considerations for prior authorization of a new therapy will be determining which PBC patients are appropriate candidates for the new therapy and developing criteria for that determination. These are likely to include clinical diagnostic criteria and degree of response to prior treatment with UDCA. Initially, any new therapy would likely be positioned as noncovered until appropriate prior authorization criteria are established.

CONCLUSIONS: PBC is a chronic liver disease with significant morbidity and mortality, as well as a significant burden on the health care system if the disease progresses to the point at which a liver transplant is needed. Although UDCA, the current standard of care, has improved outcomes for many patients, others have an inadequate response to this treatment. This symposium discussed these issues and also addressed the overall treatment paradigm for orphan drug therapies, key implications for patient management, and the role of specialty pharmacy management and any associated needs both in general and specifically for new therapeutic options for PBC.

\section{J Manag Care Spec Pharm. 2016;22(10-a):S3-S15}

Copyright $\odot 2016$, Academy of Managed Care Pharmacy. All rights reserved.

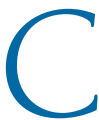

hronic liver disease and cirrhosis is estimated to be the twelfth leading cause of death in the United States ${ }^{1}$ and the fourth leading cause of death for adults aged between 45 and 54 years. ${ }^{2}$ According to the Centers for Disease Control and Prevention, liver-related mortality in the United States was estimated at about 11 deaths per 100,000 in 2008. ${ }^{1}$ When liver-related mortality from viral hepatitis, liver cancer, hepatic encephalopathy, hepatorenal syndrome, and additional complications from liver disease are considered, mortality estimates are in excess of 25.7 deaths per 100,000; estimates vary considerably when stratified by race and ethnicity (Figure 1). ${ }^{1}$

One of several chronic liver diseases, primary biliary cirrhosis, recently renamed primary biliary cholangitis (PBC), is a chronic autoimmune disease resulting in destruction of the small bile ducts in the liver. In the absence of effective treatment, disease progression will potentially lead to liver failure and death. Ursodiol, also referred to as UDCA, is the only U.S. Food and Drug Administration (FDA)-approved treatment for $\mathrm{PBC}{ }^{3}$ Although UDCA can slow the progression of liver damage due to $\mathrm{PBC}, 1$ out of 3 patients has an inadequate response. ${ }^{4,5}$ Incomplete response to UDCA has been linked to poor outcomes. To address this unmet need, new therapies that may provide clinical benefit for patients diagnosed with PBC are in development.

To provide pharmacists with an overview of the latest research on the pathophysiology of $\mathrm{PBC}$, including characterization of the condition in the context of chronic liver disease and the unmet need for new treatment options, and to highlight medical and specialty pharmacy approaches to managing access to drugs to treat orphan diseases, a 2-hour satellite symposium was presented in conjunction with the AMCP Nexus meeting on October 28, 2015. The symposium was supported by an independent educational grant from Intercept Pharmaceuticals. Robert Navarro, PharmD, Clinical Professor at the University of Florida College of Pharmacy, 


\section{FIGURE 1 Liver-Related Mortality, 2008}

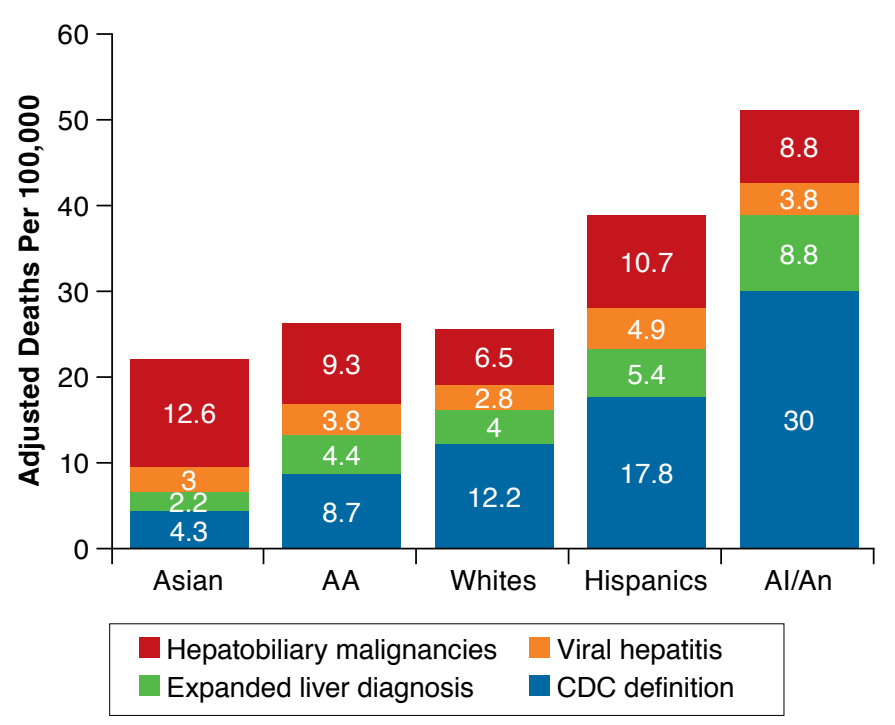

Percent of overall liver-related deaths in 2008 by the predefined categories and stratified by race. $C D C$ definition is based on the underlying cause of death being chronic liver disease and cirrhosis, which corresponds to a single ICD-9 code of 571 and ICD-10 codes of K70, K73, and K74. Expanded liver diagnosis reflects additional diagnoses specific to liver disease yet excluded in the CDC definition. The sum of all the rates within each bar comprises the updated estimate of liver-related mortality by race. Adjusted to U.S. Census 2000 population, only individuals older than 15 years are considered at risk.

$A A=A$ frican American; $A I / A N=$ American Indian and Alask Native; $C D C=$ Centers for Disease Control and Prevention; ICD = International Classification of Diseases. Reprinted from Gastroenterology, vol. 145, no. 2, SK Asrani, JJ Larson, B Yawn, TM Therneau, WR Kim, Underestimation of liver-related mortality in the United States, 2013, pp. 375-82, with permission from Elsevier (http://www.sciencedirect. com/science/journal/00165085). ${ }^{1}$

moderated the CPE-accredited symposium titled "Medical and Specialty Pharmacy Management Update on Primary Biliary Cirrhosis." Symposium panel members included Christopher L. Bowlus, MD, Professor of Medicine and Chief in the Division of Gastroenterology and Hepatology at the University of California, Davis, Medical Center; James T. Kenney, RPh, MBA, Manager, Specialty and Pharmacy Contracts for Harvard Pilgrim Health Care (HPHC); and Gary Rice, RPh, MS, MBA, CSP, Senior Vice President of Clinical, Education, and Human Resources Services at Diplomat Pharmacy.

The presentations at the satellite symposium were designed to (a) present a PBC disease overview, including clinical management and an update on new drug therapies in development; (b) describe a health plan pharmacy benefit approach to managing new drug therapies for rare diseases such as PBC; and (c) characterize the role that the specialty pharmacy plays in drug distribution, patient management, and outcomes management for an orphan disease. This article presents a summary of the satellite symposium, highlighting updates in the medical and specialty pharmacy management of $\mathrm{PBC}$. Although obeticholic acid (OCA) was approved by the FDA for the treatment of PBC in May 2016, ${ }^{6}$ this development occurred after the symposium presentation.

\section{Primary Biliary Cholangitis, Current Clinical} Management, Unmet Need, and Potential New Therapies on the Horizon

\section{Disease Description}

Liver diseases can be categorized as either common or rare Common chronic liver diseases that account for the majority of documented cases include nonalcoholic fatty liver disease, alcoholic liver disease, and viral hepatitis B and C. Rare liver diseases can be further classified as either genetic or autoimmune and together account for 15\% of all liver transplants performed and an equal percentage of deaths related to liver disease. ${ }^{7,8}$ Genetic liver diseases include hereditary hemochromatosis, alpha-1 antitrypsin deficiency, and a rare copperrelated condition known as Wilson disease. PBC falls into the category of autoimmune liver diseases, along with primary sclerosing cholangitis (PSC) and autoimmune hepatitis (AIH). ${ }^{1}$

PBC was first described in 1851 in 3 patients with jaundice, hepatomegaly, and xanthelasma, and antimitochondrial antibodies (AMAs) were identified as a diagnostic criterion in 1965. ${ }^{9}$ Although clinical presentation is variable in patients with PBC, AMAs are observed in nearly $90 \%$ of all patients. A female predominance, not uncommon to autoimmune diseases in general, is even more striking in $\mathrm{PBC}$, with female patients accounting for $90 \%$ of diagnosed new cases.

The diagnosis of $\mathrm{PBC}$ requires the presence of 2 out of 3 of the following criteria: (a) persistent elevation of serum alkaline phosphatase, (b) presence of AMAs, and (c) a liver biopsy consistent with PBC. ${ }^{10}$ In about $10 \%$ of cases, AMA is negative, and a liver biopsy is required to confirm a PBC diagnosis. ${ }^{10}$ In response to a question addressed to the panel about whether a liver biopsy is necessary for AMA-negative patients, or if FibroSURE or FibroScan is able to detect abnormalities, Bowlus shared his view that a liver biopsy is needed because certain noninvasive markers, such as FibroSURE and FibroScan, only provide an indirect measure of fibrosis, not a histologic view of the underlying pathology. A liver biopsy will validate injury to the bile duct as the cause of the elevation of the alkaline phosphatase for a definitive diagnosis of PBC.

Delayed diagnosis is obviously very common for rare diseases in general. It's not unheard of and no different here. It's not uncommon for patients to wait 8 to 10 years to get that final diagnosis from the time they initially had an abnormal liver test, and that obviously can have consequences in terms of response to therapy, progression of disease. —Christopher L. Bowlus, MD 
Population-level studies for PBC are lacking, and trends indicate an increase in prevalence that may be attributed to increasing case identification. The reported prevalence of PBC in women aged more than 40 years was 1,558 cases per million (95\% confidence interval=294-3,815). ${ }^{11}$ If ongoing research confirms the presence of AMAs in asymptomatic individuals resulting in eventual disease progression, PBC classification may increase the disease burden beyond rare disease status. ${ }^{12}$

Although most often characterized in middle-aged Caucasian women, PBC has been described in a variety of ethnic groups. ${ }^{13}$ The presentation of the disease is possibly more severe in Hispanic patients. A cross-sectional study analyzed the demographics, clinical presentation, therapy response, and outcomes between Hispanic $(n=70)$ and non-Hispanic patients $(n=134)$ with PBC. ${ }^{13}$ The results of the study in Hispanic patients demonstrated a reduced response to UDCA and a higher rate of complications. ${ }^{13}$ Recent epidemiological data from China also confirms increasing rates of PBC, possibly because of increased awareness of diagnostic methodology.

Although an exact cause of PBC has not been identified, the etiology of $\mathrm{PBC}$ is thought to originate from a combination of genetic predispositions and environmental triggers. Environmental exposure to xenobiotics is thought to trigger a loss of tolerance to the mitochondrial antigen pyruvate dehydrogenase E-2 subunit (PDC-E2), which leads to an immune attack involving AMAs, and CD4 and CD8 T cells, and to defects in regulatory $\mathrm{T}$ cells with eventual bile duct damage. ${ }^{9}$ The immune reaction of $\mathrm{PBC}$ is to a specific moiety on PDC-E2, called lipoic acid.

The hallmark of autoimmune attack to the biliary epithelial cells present in the liver is the highly specific antimitochondrial response, which results in elevated serum alkaline phosphatase in the absence of apparent obstruction. In a normal cell, when electron transfer occurs during oxidative phosphorylation in the mitochondria, the lipoyl or disulfide ring opens and closes on the PDC-E2 protein. ${ }^{14}$ While in its reduced state, the lipoic acid is susceptible to modification, which could potentially lead to an immunogenic PDC-E2 and the breakdown of selftolerance to PDC-E2.

Supporting this hypothesis was the finding that serum from patients with $\mathrm{PBC}$ demonstrates reactivity to a variety of chemicals with similar structure to lipoic acid. ${ }^{14}$ Additional research by Naiyanetr et al. (2011) demonstrated that the replacement of lipoyl residues with xenobiotic mimics such as 2-octynoic acid and 2-nonynoic acid increases the potential for further PDC-E2 modification. ${ }^{15}$ The chemical 2-octynoic acid is found in cosmetics and a variety of other products. Epidemiologic studies demonstrating clustering of $\mathrm{PBC}$ cases around toxic waste sites in New York City and urban areas of northeast England further support the xenobiotic hypothesis. ${ }^{16}$

In addition to the break in tolerance, the targeting of the biliary epithelial cell is an important point in the pathophysiology

\section{FIGURE 2 Trends in Liver Transplants for} Autoimmune Liver Diseases

(A)

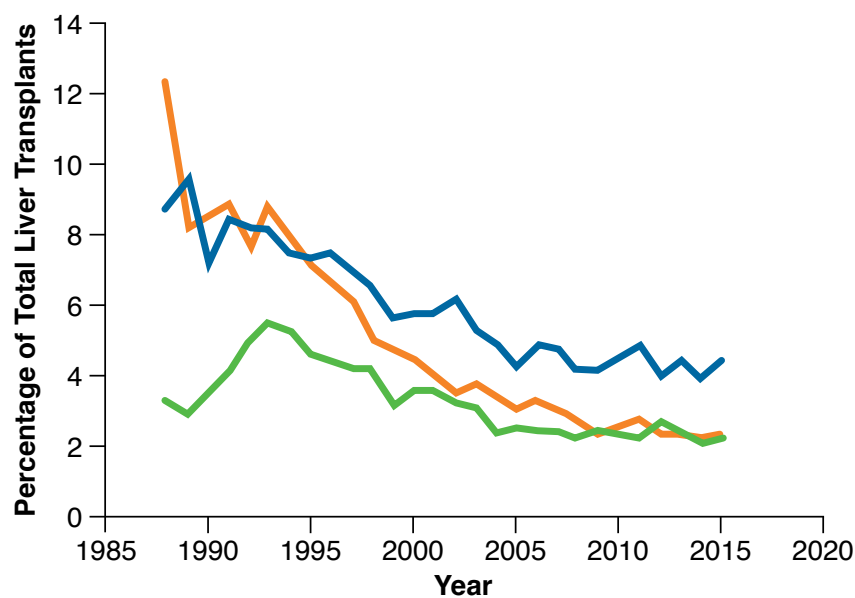

(B)

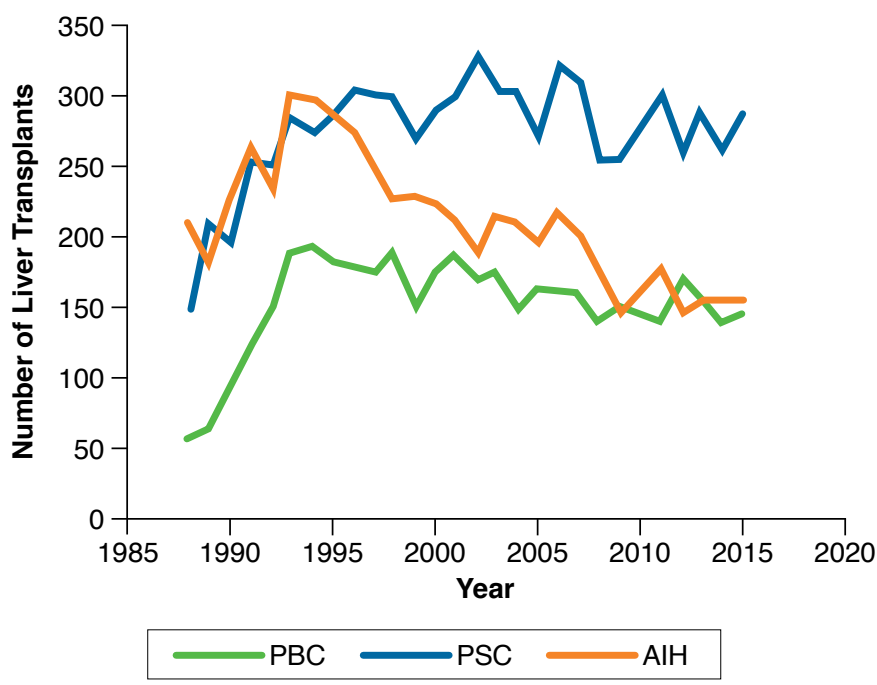

As a proportion of all liver transplants, PBC, PSC, and AIH have been decreasing since 1989 (A). The absolute number of liver transplants attributed to AIH and PSC has remained relatively stable due to the absence of new and effective therapies, whereas the absolute number of transplants due to PBC has significantly decreased over the last 15 to 20 years since the introduction of UDCA (B).

$A I H=$ autoimmune hepatitis; $P B C=$ primary biliary cholangitis; $P S C=$ primary sclerosing cholangitis; UDCA = ursodiol.

Data from U.S. Department of Health \& Human Services, Organ Procurement and Transplantation Network.7

of PBC. Mitochondria are present in virtually all cells, yet only the specific cells of the biliary tract appear to be the target of an aberrant immune response. The answer to this mystery appears to be the incomplete breakdown and preservation of the PDC-E2 epitope during biliary epithelial apoptosis. This leaves the modified and immunogenic PDC-E2 immunologically intact and 


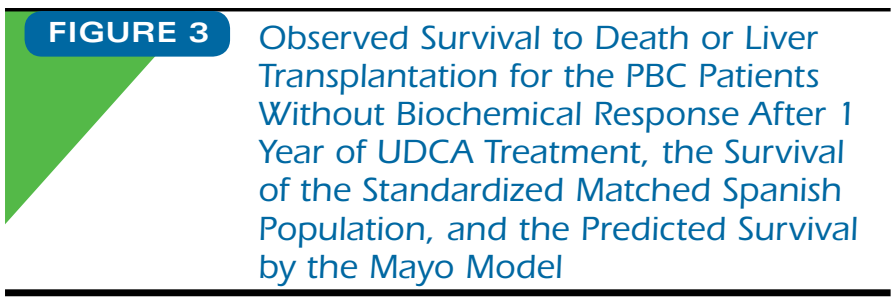

Survival

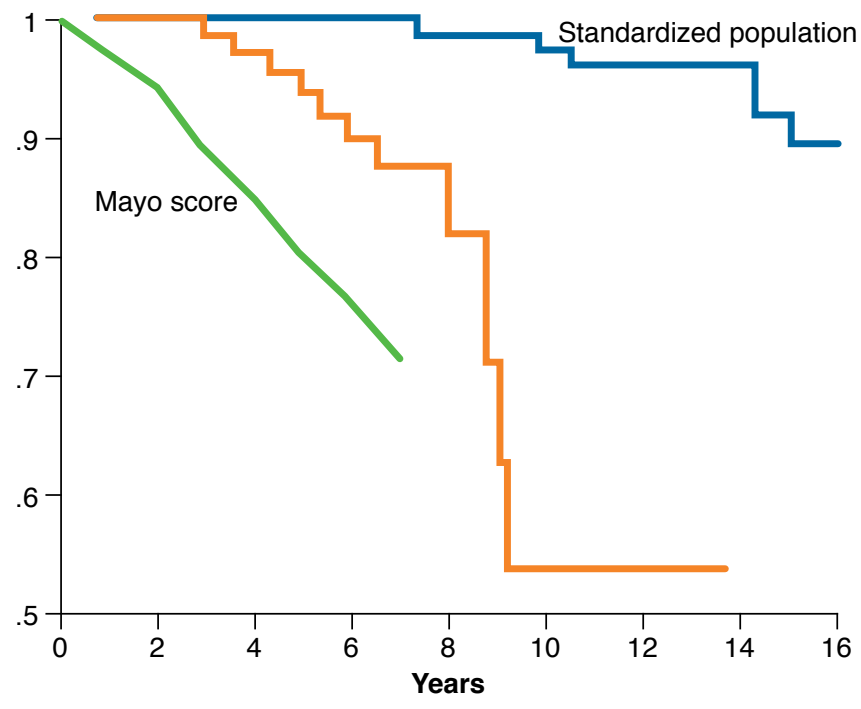

The survival observed in patients treated for UDCA for 1 year without biochemical response was higher than the survival predicted by the Mayo model $(P<0.001)$ but significantly lower than that of the standardized matched Spanish population $(P<0.001)$. UDCA = ursodiol.

Reprinted from Gastroenterology, vol. 130, no. 3, A Pares, L Caballeria, J Rodes, Excellent long-term survival in patients with primary biliary cirrhosis and bio-

chemical response to ursodeoxycholic acid, pp. 715-20, 2006, with permission from Elsevier (http://www.sciencedirect.com/science/journal/00165085). ${ }^{30}$

accessible to immune cells, ${ }^{17}$ resulting in an immune-mediated cholangitis (or destruction of bile duct cells). ${ }^{18}$

Clinically, this cholangitis is observed as an elevation of alkaline phosphatase. Loss of duct cells (or ductopenia) leads to cholestasis and possible pruritus. If the disease progresses to cirrhosis, portal hypertension and subsequent complications can develop, such as variceal bleeding, the need for liver transplantation, and death due to liver disease.

\section{Clinical Manifestations and Burden}

Before the introduction of UDCA, the course of $\mathrm{PBC}$ was associated with very poor outcomes. Severity of the disease is typically assessed according to the following staging criteria: Inflammation is limited to the portal space in stage I, inflammation spreads to the periportal areas in stage II, septal fibrosis or inflammatory bridging is the hallmark of stage III, and cirrhosis occurs in stage IV. ${ }^{19}$ In a 1996 study by Locke et al., more than half of the patients who were classified as having stage I disease at baseline progressed; by year 4 , only $18 \%$ of patients remained at stage I, and $31 \%$ were at stage IV. ${ }^{18}$ These results demonstrate the escalating nature of $\mathrm{PBC}$ in the absence of effective treatment.

Unchecked disease progression can lead to poor outcomes, including the need for liver transplantation and liver-related mortality. Since the 1990s, the number of liver transplants for each of the 3 autoimmune conditions (PBC, PSC, and AIH) has decreased as a proportion of all liver transplants (Figure 2). ${ }^{7}$ However, the absolute number of liver transplants attributed to AIH and PSC has remained relatively stable because of the absence of new and effective therapies, whereas the absolute number of transplants because of PBC has significantly decreased over the last 15 to 20 years since the introduction of UDCA.

Viral-related and alcoholic liver cirrhosis represent the first and second most frequent reasons for liver transplantation, respectively, while $\mathrm{PBC}$ is the third most frequent cause. Recurrent PBC occurs in $21 \%-37 \%$ of patients at 10 years after a liver transplant and increases to $40 \%$ at 15 years (median time of recurrence is 3 to 5.5 years). ${ }^{20}$ Therefore, further reduction of the number of liver transplants could help lessen the economic burden of $\mathrm{PBC}$ on the health care system-the average cost of a liver transplant in the United States is $\$ 739,100$, based on 2014 billed charges. ${ }^{21}$

In addition to the hepatic burden, nonhepatic symptoms associated with $\mathrm{PBC}$ have a clinically significant impact on quality of life (QoL) for some patients. Fatigue is the most commonly reported symptom and was considered to be moderately to extremely important in 33\% of patients responding to 2 validated questionnaires. ${ }^{22}$ Fatigue is difficult to characterize and measure in any disease, including $\mathrm{PBC}$, and does not seem to be related to depression in $\mathrm{PBC}$ patients as it is in some other conditions. A study in northeast England found higher rates of fatigue in PBC patients compared with controls ${ }^{23}$; however, studies in the United States and in Sweden have not reported a significant difference in fatigue scores between PBC patients and controls. ${ }^{22,24}$ Clinical severity of fatigue does not appear to be correlated with liver disease severity in PBC patients. ${ }^{4}$

Pruritus is another symptom commonly reported by $\mathrm{PBC}$ patients. It is mild in a majority of patients but presents a difficult QoL challenge for the minority who experience severe pruritus. High rates of osteopenia and osteoporosis have also been reported among $\mathrm{PBC}$ patients. ${ }^{9}$

\section{Current Clinical Management}

Currently, UDCA is the only FDA-approved therapy for the treatment of $\mathrm{PBC}$ and is considered to be the standard of care. The recommended adult dosage of UDCA tablets for oral use is 13-15 mg per $\mathrm{kg}$ per day administered in 2-4 divided doses with food. ${ }^{25}$ In the 1990s, UDCA was studied in 5 


\begin{tabular}{|c|c|}
\hline TABLE 1 & $\begin{array}{l}\text { Definitions for Biochemical } \\
\text { Response to UDCA }\end{array}$ \\
\hline Criteria & Definition \\
\hline Barcelona & $\begin{array}{l}\text { - Decrease in alkaline phosphatase level }>40 \% \text { of } \\
\text { baseline level or a normal level }\end{array}$ \\
\hline $\begin{array}{l}\text { Paris I } \\
\text { (all criteria met) }\end{array}$ & $\begin{array}{l}\text { - Alkaline phosphatase level } \leq 3 \times \mathrm{ULN} \\
\text { - Aspartate aminotransferase level } \leq 2 \times \mathrm{ULN} \\
\text { - Normal bilirubin level }\end{array}$ \\
\hline $\begin{array}{l}\text { Paris II } \\
\text { (all criteria met) }\end{array}$ & $\begin{array}{l}\text { - Alkaline phosphatase level } \leq 1.5 \times \mathrm{ULN} \\
\text { - Aspartate aminotransferase level } \leq 1.5 \times \mathrm{ULN} \\
\text { - Normal bilirubin level }\end{array}$ \\
\hline $\begin{array}{l}\text { Toronto } \\
\end{array}$ & - Alkaline phosphatase level $<1.67 \times$ ULN \\
\hline \multicolumn{2}{|c|}{$\begin{array}{l}\text { UDCA = ursodiol; ULN = upper limit of normal. } \\
\text { Adapted from Carbone M, Mells GF, Pells G, et al. Sex and age are determinants of the } \\
\text { clinical phenotype of primary biliary cirrhosis and response to ursodeoxycholic acid. }{ }^{4}\end{array}$} \\
\hline
\end{tabular}

randomized, placebo-controlled trials in $\mathrm{PBC}$ patients (stages I-IV) with positive but mixed findings. In the first of these trials, 180 patients at the Mayo Clinic saw delayed progression of disease, with limited effect on liver biopsy histology, symptoms, progression to liver transplantation, and survival ${ }^{5}$; a Canadian study of 222 patients found similar results. ${ }^{26} \mathrm{~A}$ multicenter U.S. study of 151 patients observed the largest improvement in histology with UDCA in less severe patients (bilirubin $<2 \mathrm{mg}$ per $\mathrm{dL}$ and early-stage histology). ${ }^{27} \mathrm{~A}$ European study of 145 patients reported a reduction in rates of disease progression, liver transplantation, and death. ${ }^{28}$ Finally, a Spanish study of 192 patients found improved histology but no effect on survival or liver transplantation. ${ }^{29}$ Most of these clinical trials had a 2-year treatment period, making it difficult to observe long-term clinical outcomes in patients with PBC, which is a chronic, slowly progressing disease. Although most of the endpoints are histologic changes, some studies were also able to demonstrate a delay in liver transplantation. ${ }^{3}$

A post hoc analysis of the Spanish trial examined patients according to biochemical response to UDCA, including total bilirubin, alkaline phosphatase, and albumin levels as well as prothrombin time. ${ }^{30}$ This analysis demonstrated that patients whose serum alkaline phosphatase decreased by $40 \%$ from baseline or normalized had survival similar to a standardized population. Patients lacking this biochemical response did slightly better than what was predicted but clearly worse than a comparable population group (Figure 3). ${ }^{30}$

Because of the various endpoints used in the clinical trials, several sets of criteria for defining response to UDCA have been proposed; these include the Barcelona criterion, Paris I and Paris II criteria, and Toronto criterion (Table 1). In addition to these, other classification strategies are also being developed. Carbone et al. (2013) examined a United Kingdom cohort of several thousand patients and used these 4 systems to classify patients as responders or nonresponders. Regardless of which criteria were used, there was clear separation between responders and nonresponders in terms of survival outcomes. ${ }^{4}$

Specific subgroups of patients have been identified as less likely to respond to treatment, including women diagnosed at an earlier age and men regardless of age. Earlier treatment is beneficial because it often leads to better outcomes. ${ }^{4}$ In addition, patients with AMA-negative PBC do not differ in survival rates or biochemical response to UDCA. ${ }^{10}$

\section{Clinical Course and Unmet Need: 2 Examples of Typical Patient Journeys}

To illustrate the difference in the typical clinical course between a responder and a nonresponder to UDCA, Bowlus presented the case histories of 2 patients from his practice. The first patient, a 55-year-old woman, was found during screening to have elevated cholesterol despite reporting dietary and lifestyle modifications. Before a statin was started, a standard liver enzyme panel showed an elevated alkaline phosphatase, a mildly elevated alanine aminotransferase, and normal bilirubin levels. Work-up of the abnormal liver tests revealed a positive AMA, and the diagnosis of $\mathrm{PBC}$ was made based on elevated alkaline phosphatase and AMA positivity. Bowlus prescribed an initial dose of UDCA at $15 \mathrm{mg}$ per kg daily by mouth in divided doses. The patient's alkaline phosphatase decreased from a baseline of 346 IU to normal levels within a few months, and it has remained stable. This profile reflects a typical responder to UDCA, and the patient will likely not experience disease progression.

The second patient was a woman aged less than 50 years with an alkaline phosphatase of nearly $700 \mathrm{IU}$, about twice the level of the prior patient. After starting on UDCA, she exhibited a limited and fluctuating improvement in her alkaline phosphatase; however, after 5 years her levels did not normalize. In addition, her bilirubin levels, initially within normal range, started to rise. The patient developed esophageal variceal bleeding, and liver transplantation is now a likely outcome.

Clearly, [ursodiol] is effective, but the response is variable, and about a third of the patients do not respond, and nonresponders have a greater risk of disease progression and higher mortality risk.

—Christopher L. Bowlus, MD

Nonresponders to UDCA have a greater risk of disease progression, have a higher mortality risk, and are more likely to require liver transplantation. ${ }^{9}$ Some evidence suggests a benefit from fibrates. ${ }^{31,32}$ The use of immunosuppressants to target inflammation has been disappointing, and effectiveness has been limited. Steroids such as prednisone and budesonide have demonstrated potential benefits, but long-term use is not 


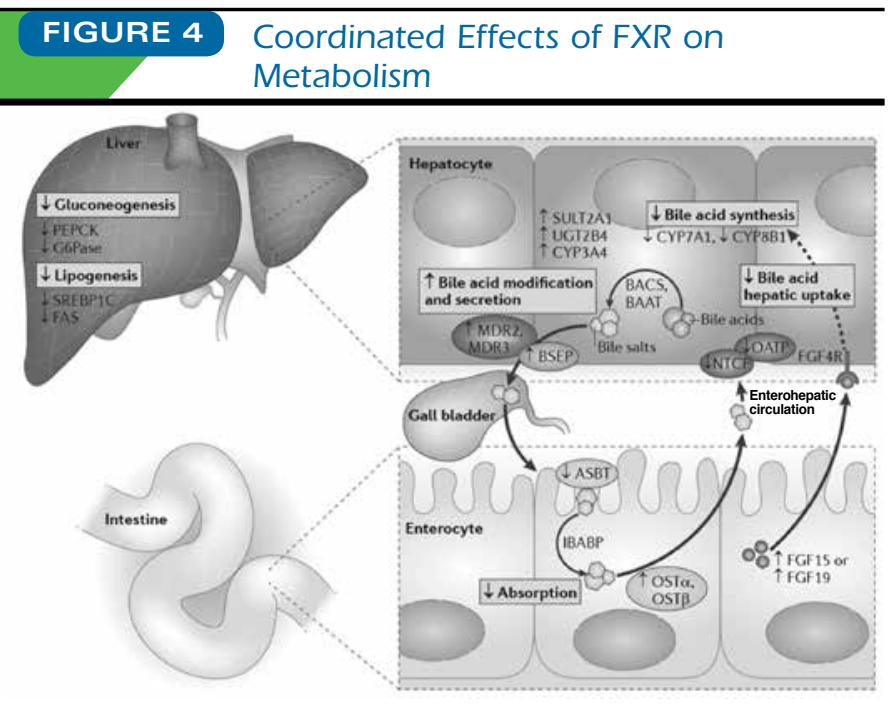

Farnesoid X receptor (FXR) mediates effects on multiple metabolic pathways in a tissue-specific manner. In the liver, FXR reduces conversion of cholesterol to bile acids by downregulating the expression of enzymes involved in bile acid synthesis, such as cytochrome P450 7A1 (CYP7A1) and CYP8B1. FXR also reduces bile acid toxicity in the liver by increasing other bile acid-modifying enzymes, including sulphotransferase 2A1 (SULT2A1), UDP-glucuronosyltransferase 2B4 (UGT2B4), and CYP3A4. Bile acids are conjugated to either glycine or taurine before secretion into the bile; FXR enhances bile acid conjugation by increasing the expression of bile acid CoA synthase (BACS) and bile acid CoA-amino acid N-acetyltransferase (BAAT), and FXR promotes the transport of bile acids to the gall bladder via bile salt export pump (BSEP), multidrug resistance protein 2 (MDR2), and MDR3 (membrane transport proteins are depicted as ovals). Within the intestine, FXR reduces bile acid absorption via downregulation of the apical sodium-dependent bile acid transporter (ASBT), promotes bile acid movement across the enterocyte via ileal bile acid binding-protein (IBABP), and promotes recycling of bile acids to the liver via organic solute transporter- $\alpha(O S T \alpha)$ and OST $\beta$. In addition, FXR reduces hepatic uptake of bile acids by reducing the expression of organic anion transporting polypeptide (OATP) and sodium taurocholate cotransporting polypeptide (NTCP). FXR also promotes the release of fibroblast growth factor15 (FGF15) in mice and FGF19 in humans from the intestine. FGF15 and FGF19 travel to the liver, acting on FGF4 receptor (FGF4R) to reduce CYP7A1 expression and thus repress bile acid synthesis. In the liver, FXR also acts on glucose metabolism by reducing gluconeogenesis via the downregulation of phosphoenolpyruvate carboxykinase (PEPCK) and glucose-6-phosphatase (G6Pase), two key enzymes in the glucose synthesis pathway. Furthermore, FXR reduces lipogenesis via inhibition of sterol-regulatory elementbinding protein 1C (SREBP1C) and fatty acid synthase (FAS).

Reprinted by permission from Macmillan Publishers Ltd: Nature Reviews Molecular Cell Biology, vol. 13, no. 4, AC Calkin, P Tontonoz, Transcriptional integration of metabolism by the nuclear sterol-activated receptors LXR and FXR, pp. 213-24, 2013 (http://www.nature.com/nrm/index.html). ${ }^{39}$

recommended because of the side-effect profiles. ${ }^{3}$ Liver transplantation is curative for the majority of patients, but it is a costly and invasive procedure. Therefore, $\mathrm{PBC}$ patients who do not respond to treatment with UDCA require new therapeutic options to improve clinical outcomes.

\section{Potential New Therapies on the Horizon}

Combination Therapy with UDCA. A meta-analysis of 7 longterm randomized controlled trials $(n=177)$ comparing bezafibrate and UDCA combination therapy versus UDCA monotherapy found that the combination therapy of bezafibrate plus UDCA was more effective than UDCA monotherapy in improving liver biochemistry (mean difference in alkaline phosphatase -146.15 IU per L; $P<0.001) .{ }^{31}$ Also, there was no significant difference in the rate of adverse events (AEs; odds ratio $[\mathrm{OR}]=0.35 ; P=0.22$ ) or all-cause mortality incidence $(\mathrm{OR}=0.72 ; \mathrm{P}=0.75)$ between patients treated with combination therapy or monotherapy. ${ }^{31}$ Bowlus noted that combination therapy with bezafibrate and UDCA appears to be effective in terms of improving biochemistries, but the clinical impact and safety are unclear.

Additional combination studies of UDCA and oral budesonide include 3 smaller clinical trials that demonstrate biochemical and histologic improvement. However, there is still concern about long-term use of this combination, since all 3 studies demonstrated complications and AEs associated with budesonide. ${ }^{33-35}$

FXR Receptor Agonist. Bowlus explained that the farnesoid $\mathrm{X}$ receptor (FXR) has recently generated considerable interest because of its role in bile acid synthesis and its regulation (Figure 4). Bile acids are produced in the liver by hepatocytes and are excreted through the biliary system into the intestine. They are then absorbed in the terminal small intestine or terminal ileum through the apical sodium bile acid transporter (ASBT) and recirculated to the liver. Bile acids are produced from cholesterol in a process regulated primarily through FXR. The activation of FXR causes decreased bile acid uptake by hepatocytes, decreased bile acid synthesis, and decreased reabsorption by downregulation of ASBT. The result is a decrease in the bile acid pool that is thought to be the mechanism of action for reducing the injury in PBC.

A selective FXR agonist, OCA, was recently studied in a double-blind, placebo-controlled phase 3 trial (POISE). $\mathrm{PBC}$ patients with an incomplete response or who were intolerant to UDCA were randomized to receive OCA $10 \mathrm{mg}$ daily $(\mathrm{n}=73)$, OCA $5 \mathrm{mg}$ daily titrated to $10 \mathrm{mg}$ daily at 6 months $(n=70)$, or placebo $(n=73)$ for 12 months. ${ }^{36}$ Response was defined using the Toronto criterion (alkaline phosphatase level $<1.67$ times the upper limit of normal), with at least a $15 \%$ reduction in alkaline phosphatase and normal bilirubin. A statistically greater proportion of patients receiving OCA met the response criteria (46\% and $48 \%$ in the $5 \mathrm{mg}$ titration and $10 \mathrm{mg}$ groups, respectively) compared with the placebo group (10\%; $P<0.001) .{ }^{37}$ Dose-related reports of pruritus were observed and led to discontinuation in $1 \%$ and $10 \%$ of patients in the $5 \mathrm{mg}$ titration and $10 \mathrm{mg}$ groups, respectively. No serious study drug-related AEs were reported. ${ }^{36}$

\section{Managing New Drug Therapies for PBC Within a Health Plan Pharmacy Benefit}

James T. Kenney, RPh, MBA, Manager, Specialty and Pharmacy Contracts at HPHC, continued the discussion with a 
presentation from the perspective of a regional managed care health plan that covers more than 1.3 million lives. HPHC operates a commercial line of business, a Medicare Part D product, and has 3 state exchange products in Massachusetts, Maine, and New Hampshire. Kenney discussed current approaches to the management of the pharmacy benefit and specialty pharmacies in this context. He then discussed PBC patients, describing the patient journey, how pharmacy benefits are typically managed for serious medical conditions, and considerations for any new therapies that may be introduced.

\section{Current Approaches to Management of Pharmacy Benefit and Specialty Pharmacy}

Kenney began his discussion of HPHC's current approach to managing the pharmacy benefit by first characterizing its 2 core benefit designs: an open formulary design with 3- and 4-tier options and a closed formulary design with 4- and 5-tier options, adding that a specialty tier may be included on the closed formulary as tier 4 or 5 . In general, copay structure design varies by the employer groups with which a plan contracts. With the open formulary, new drugs will be covered on the formulary when they enter the market unless there is an exclusion of the category to which they belong. On the closed formulary, as a new drug launches, the default position is "not covered"; prior authorization and utilization criteria may then be developed as needed for different products. The objective of the prior authorization process is to ensure that the products are used appropriately and targeted for use with the right patient. Other utilization management tools that may be used include step edits, quantity limits, a specialist prescribing requirement, and age or sex edits.

Essentially what we're trying to do is control for inappropriate use of a product. [The perception] in the market is often that the prior authorization is designed to make physicians' lives difficult ... but in reality what we're trying to do is maximize the opportunity to use these products appropriately and target them for the correct patient to achieve the best possible outcomes.

$$
\text { —James T. Kenney, RPh, MBA }
$$

Specialty pharmacies may be used for limited distribution drugs (a) when shipping to a patient or provider is needed, (b) when care or case management services in a particular disease area will be used, (c) to assist in the development of prior authorization criteria, (d) to share knowledge and experience on utilization and management from other health plans, and (e) as a resource on a disease state. Mandatory specialty pharmacy distribution may be used; however, this requirement is not allowed for Medicare Part D. Whether a drug is designated by HPHC as specialty pharmacy depends on a range of definitions. For a Medicare line of business, a drug is typically designated as specialty if it costs more than $\$ 600$ a month. ${ }^{38}$ In general, in a commercial line of business, the assessment of whether the assignment to specialty pharmacy is warranted depends on whether the designation will provide value to the plan and whether it will result in more appropriate utilization or increased treatment effectiveness.

For orphan or rare diseases, specialty assignment has several advantages. The specialty pharmacy provides valuable disease education to a health plan, including help with designing well-informed and appropriate prior authorization criteria, and they provide expertise to the patients. A typical retail pharmacy in the network may see 1 patient with a rare disease across many years, whereas a specialty pharmacy may have experience with hundreds of these patients. The specialty pharmacy also has pharmacist, nursing, and physician services that enhance access and adherence to the medications by the appropriate patients. Specialty pharmacy expertise may come in the form of helping patients understand the approach to treatment and living with the disease, with side-effect management, if relevant, or with compliance/adherence programs. This expertise is expected to lead to improved response to treatment and superior outcomes.

Part of HPHC's goal in using a specialty pharmacy is to tap into this disease-specific expertise so that prior authorization criteria are established to ensure appropriate use. All drugs, including those indicated for an orphan condition or rare disease, are evaluated through the normal pharmacy and therapeutics (P\&T) committee process, which is a committee of physicians and pharmacists from the network as well as from the plan. Additionally, physician consultants provide input on an ad hoc basis. On the open formulary, a new drug defaults to a covered position on the highest tier, and then the P\&T committee evaluates whether to move the drug to a preferred status. Any utilization management criteria for the open formulary must be applied at launch to comply with regulatory restrictions.

In general, an oral drug is assigned to the pharmacy benefit. Drugs that are assigned to the medical benefit are those that are administered by a physician or other health professional. With a fully integrated medical and pharmacy data warehouse, a plan has the capability to manage patients across both benefits. A review of the medical claims database provides information on how many patients have a diagnosis of a condition such as $\mathrm{PBC}$, which helps in evaluating the potential impact of a disease to a health plan and to the patients' pharmacy or medical benefit budget.

\section{Patient Journey and Burden of PBC from a Health Plan Perspective}

Kenney presented an overview of a typical PBC patient journey. Echoing earlier comments by Bowlus, he noted that diagnosing 
rare liver diseases is a challenge for primary care physicians without specialized experience in this therapeutic area and that specialists typically manage these patients. With respect to the burden of a disease such as PBC, there is a recognition and expectation that the PBC patient is experiencing a number of symptoms, such as fatigue and pruritus, and is likely to be already receiving treatment with UDCA or have had claims in the past. The plan also looks at medical resource utilization, which can be assessed using administrative claims data.

A manufacturer's distribution plan has a major impact on how quickly a patient may have access to a new drug. For example, if a manufacturer has a unique specialty pharmacy distributing the drug and it is not in the health plan's network of pharmacies, then a separate contract must be negotiated with the specialty pharmacy to ensure that claims can be exchanged and processed between the health plan and the pharmacy benefit manager. Health plans need to understand the distribution plan in advance so that they are prepared to provide access to the drug and allow claims to be processed; manufacturers will typically provide physicians and health plans with information on distribution requirements for new-to-market drugs and how they will be managed.

Patients may have additional support through copay assistance programs, and with orphan or specialty diseases, these programs provide a valuable benefit for the patient. Kenney noted that while a number of states are capping copays at a certain level, the patient's share of payment could be a significant burden, especially given the likelihood of other comorbidities requiring treatment.

The prescription can go directly to a specialty pharmacy, or it may go to a hub provided by a manufacturer that processes the prescription and then forwards it to a specialty pharmacy. Hubs can provide additional resources for the patient, process the prescriptions appropriately, and forward them to the right specialty pharmacy — and ultimately to the patient more quickly.

\section{Key Considerations for Management of New PBC Therapies}

The clinical value of any new options for managing patients is determined by efficacy, safety, and tolerability. Kenney stated that drugs entering the market today are costly, reminding the audience that the potential reduction in medical resources, hospitalizations, and emergency department visits is meaningful. If a new drug is going to prevent unnecessary liver surgeries or delay liver transplants, it will be an advantage for a health plan to cover.

What we're trying to understand is how can we better manage the patients and either delay or actually avoid some of these conditions and, again, position that drug in an appropriate manner.

$$
\text { -James T. Kenney, RPh, MBA }
$$

While there is hope that every new drug coming to market is going to offer some type of medical cost offset, there is recognition that often the cost of a new drug will not be offset. Key considerations for HPHC in managing any new drug to treat $\mathrm{PBC}$ will be whether the appropriate patient population will be all $\mathrm{PBC}$ patients or a subset thereof, and if it is a subset, how that subset will be defined. Diagnostic criteria may be used; for example, 2 of the 3 tests that Bowlus described might be required as diagnostic criteria to confirm a $\mathrm{PBC}$ diagnosis. UDCA is expected to remain first-line therapy for PBC patients, and about $60 \%$ of the patients are expected to respond. ${ }^{29}$ With authorization for a new drug for $\mathrm{PBC}$ patients, response to UDCA at 6 months will be assessed, most likely based on physician attestation, which is an efficient approach that does not require burdensome documentation. If a patient has not responded, then treatment with the next therapeutic option for PBC patients will be authorized. Reauthorization will likely occur at 6 to 12 months. In response to a question from Navarro, the session moderator, regarding potential concerns about nonresponders or incomplete responders who are at risk for significant morbidity or mortality, Kenney noted that plans will rely on key opinion leaders to determine the length of a trial of UDCA that will be sufficient to determine treatment response. As new products come to market or new evidence emerges, these criteria may be adjusted.

To summarize a few expectations of a specialty pharmacy in PBC management, Kenney discussed the importance of compliance/adherence and managing side effects with the assistance of a specialty pharmacy. Also, the ability to track effectiveness through reauthorization and assess whether a patient is benefiting from treatment, particularly in the context of complex rare diseases, is critical for optimizing patient management.

Symposium attendees then asked about the influence of QoL information on health plan tier assignment and determination of coverage and reimbursement for new orphan drugs. For example, attendees were interested in whether treatment effect on QoL was considered in decision making if a new drug is neutral on efficacy and safety in terms of alkaline phosphatase and biochemical metrics but is effective in managing symptoms of fatigue or depression. In response, Kenney acknowledged the limited availability of QoL data to use in the P\&T committee process but noted that, when evaluating drugs with similar efficacy, QoL data would be valuable if they were included in the FDA's evaluation of the drug. Kenney stated that the FDA's current practice does not typically include this data when evaluating drugs.

Navarro queried if orphan drugs follow typical timelines for P\&T review or if they are managed differently. Kenney replied that his organization's closed formulary would place an orphan drug launched tomorrow into the noncovered position. He continued that the intention is not to place a barrier to access 
but to establish appropriate criteria to manage the positioning of the drug within the formulary. A combined Medicare and commercial formulary requires a review of protected classes of drugs within 90 days and all other drugs within 180 days; therefore, an orphan drug would typically be assigned to the 180-day rule. At HPHC, the small populations of patients with rare diseases requiring these drugs are typically managed by medical exception requests from specialists until prior authorization criteria are established.

Navarro also sought to clarify how drugs that the FDA fast tracked were handled. Kenney replied that the health plan is more reactive to drugs with a large impact from a utilization and cost perspective, but that drug launches are typically reviewed within 60 to 90 days by a P\&T committee.

\section{Role of Specialty Pharmacy in PBC Drug Distribution,} Patient Management, and Outcomes Management

The symposium concluded with a presentation from Gary Rice, RPh, MS, MBA, CSP. Rice is the Senior Vice President of Clinical Services at Diplomat Pharmacy, the largest independent specialty pharmacy in the United States. Diplomat uses the concept of Centers of Excellence, in which pharmacists, nurses, patient care coordinators, and support staff become experts in certain therapeutic classes. This expertise enables them to deliver therapeutic management and assistance to patients, including those with orphan diseases, who are on a complex journey through diseases and therapies. A patient's journey starts with a prescription intake and extends through refill management, with several processes occurring simultaneously.

A specialty pharmacy monitors the drug development pipelines, with a focus on drugs that are expected to launch in 18 to 24 months. The first step in assessing the likely patient journey is gaining an understanding of the process through which patients obtain access to a new drug, including prior authorization criteria and approval, and relative affordability of the drug. In addition, the specialty pharmacy determines whether the evaluation of drug effectiveness is based on monitoring using laboratory tests, as with PBC. Laboratory monitoring represents an additional cost to patients and may require further coordination if patients have to obtain services from a separate laboratory instead of a physician's office. Specialty pharmacies coordinate with the physician and the patient, ensuring that the patient is obtaining the required laboratory services so the patient can be managed optimally. Finally, a specialty pharmacy wants to assess the programs and qualifications for financial support, such as copay assistance and funding from not-for-profit agencies.

In helping to shape the patient's journey, specialty pharmacies review drug efficacy, safety, and tolerability using pivotal trial data, including dosing, AEs, discontinuation rates, and associated reasons for discontinuation. In addition, a specialty pharmacy may review patient-reported outcome data from such trials. Increasingly, there are more pivotal studies that include a validated questionnaire to collect patient-reported outcomes, making these data available for use by specialty pharmacies so they can help patients understand how a new treatment may affect symptoms or quality of life.

A PBC patient's experience can be maximized through patient training and education. Clinical trial data may indicate when a drug is likely to be titrated as a patient starts therapy; this information will be included with other information developed to educate patients on side-effect management. With a treatment option where pruritis might need to be managed, a prophylactic starter kit might include an antihistamine. A starter kit also includes information directing patients to notify the specialty pharmacy in addition to the physician if they experience side effects. Additional services, such as nurse adherence calls, may be included in the patient experience if side effects are expected. Compliance packaging, which makes adhering to drug therapy that is not based on a daily dose easier for a patient, may also be considered. For a once daily treatment, packaging will not be a consideration.

In the future, approaches such as vial technology, patient portals, and smartphone technology will be evaluated and introduced. Vial technology, such as "smart caps," can be used to track adherence and persistence. Patient portals enable a specialty pharmacy to send out either emails or text messages. On the basis of patients' responses to queries from a system guided by a decision tree, patients may then be referred to a clinician or in some cases transferred back to their physician's office.

Ultimately, a specialty pharmacy wants the patient to be engaged and prepared for therapy. Understanding the drug's efficacy, safety, or tolerability, as well as its effect on other parameters such as laboratory values, is important. When questioned about the value of patient-reported data from the specialty pharmacy perspective, Rice noted that patientreported data may encourage persistence because they provide evidence that supports the benefit of therapy, from a patient's perspective. He noted that managed care organizations are starting to consider data on secondary endpoints such as fatigue, reduction in pruritus, cognitive function, or gastrointestinal symptoms, since they often affect compliance and persistence behavior. If the patient becomes engaged in his or her journey through a complete understanding of the experience on a particular therapy and gains confidence, there is a higher likelihood of compliance and persistence.

We look at compliance and persistence as a surrogate marker to that patient's confidence in their care, and that confidence and understanding of care is broader than just the medication are we communicating clearly ... are we minimizing any confusion for the patients? — Gary Rice, RPh, MS, MBA, CSP 
On the initial fill of a prescription for a drug managed by a specialty pharmacy, the patient receives a preliminary clinical consultation. For example, in the case of PBC, it is expected that an introduction to the disease and therapy; the place of the new drug in therapy; the dosage, storage, and administration; and the common side effects along with mitigation strategies are provided to the patient. Patients are trained on the prophylactic starter kit and made aware that the kit and their prescription will be shipped to them. Patients are also counseled on the importance of adhering to a titration schedule or to prescribed doses if titration is not expected. Any questions from the patient are addressed at this time in an open-ended discussion. In response to a question from a symposium attendee about whether a nurse, pharmacist, or patient coordinator typically provides the initial consultation to a patient, Rice confirmed that a pharmacist addresses initial disease and medication training, as well as what to expect with regard to drug interactions or side effects. Typically a nurse then addresses side-effect management or adherence strategy. A patient care coordinator assists with any special aspects of the distribution process.

All this information is documented in a specialty pharmacy's information technology system, where an individual patient or all patients using drugs within a therapeutic class or having the same health plan can be tracked to analyze trends. A major focus of these analyses is informing strategies for optimizing adherence and persistence.

With respect to patient assistance programs, Rice noted that there are mandated and nonmandated hubs. In general, hubs offer follow-on support services to patients, which may include patient on-boarding, benefit investigation, and patient assistance programs, with the goal of helping them get access to therapy. Mandated hubs distribute prescriptions based on their rules to determine specialty pharmacies eligible to receive them. With a nonmandated hub, manufacturers typically prefer that a patient is aware of programs that provide additional resources.

\section{Conclusions}

The pharmacy CPE-accredited symposium titled "Medical and Specialty Pharmacy Management Update on Primary Biliary Cirrhosis," held at the AMCP Nexus 2015 meeting, provided an overview of the prevalence, burden, severity, long-term outcomes, and unmet needs associated with PBC. In addition to diagnostic strategies and current approaches to medical and pharmacotherapy management, new drug therapies under investigation for treatment of $\mathrm{PBC}$ were reviewed. The symposium also addressed the overall treatment paradigm for orphan drug therapies and implications for the overall management of PBC patients, as well as the role and needs associated with specialty pharmacy management.

\section{REFERENCES}

1. Asrani SK, Larson JJ, Yawn B, Therneau TM, Kim WR. Underestimation of liver-related mortality in the United States. Gastroenterology. 2013;145(2): 375-82.el-2.

2. Xu J, Murphy SL, Kochanek KD, Bastian BA. Deaths: final data for 2013. Natl Vital Stat Rep. 2016;64(2):1-119.

3. Kaplan MM, Gershwin M. Primary biliary cirrhosis. N Engl J Med. 2005; 12(353):1261-73.

4. Carbone M, Mells GF, Pells G, et al. Sex and age are determinants of the clinical phenotype of primary biliary cirrhosis and response to ursodeoxycholic acid. Gastroenterology. 2013;144(3):560-69.

5. Lindor KD, Dickson ER, Baldus WP, et al. Ursodeoxycholic acid in the treatment of primary biliary cirrhosis. Gastroenterology. 1994;106(5):1284-90

6. U.S. Food and Drug Administration. New drug approval letter. Available at: http://www.accessdata.fda.gov/drugsatfda_docs/appletter/2016/207999Or igls000ltr.pdf. Accessed September 21, 2016.

7. U.S. Department of Health \& Human Services. Organ Procurement and Transplantation Network. Available at: https://optn.transplant.hrsa.gov. Accessed September 5, 2016

8. Setiawan VW, Stram DO, Porcel J, Lu SC, Le Marchand L, Noureddin M. Prevalence of chronic liver disease and cirrhosis by underlying cause in understudied ethnic groups: The multiethnic cohort. Hepatology. July 17, 2016. Epub ahead of print.

9. Selmi C, Bowlus CL, Gershwin ME, Coppel RL. Primary biliary cirrhosis. Lancet. 2011:377(9777):1600-09.

10. Lindor K, Gershwin Me, Poupon R, Kaplan M, Bergasa N, Heathcote E. Primary biliary cirrhosis. Hepatology. 2009;50(1):291-308.

11. Liu H, Liu Y, Wang L, et al. Prevalence of primary biliary cirrhosis in adults referring hospital for annual health check-up in Southern China. BMC Gastroenterol. 2010;10:100.

12. Podda M, Selmi C, Lleo A, Moroni L, Invernizzi P. The limitations and hidden gems of the epidemiology of primary biliary cirrhosis. J Autoimmun 2013:46:81-87.

13. Levy C, Naik J, Giordano C, et al. Hispanics with primary biliary cirrhosis are more likely to have features of autoimmune hepatitis and reduced response to ursodeoxycholic acid than non-Hispanics. Clin Gastroenterol Hepatol. 2014;12(8):1398-405.

14. Chen RCY, Naiyanetr P, Shu S, et al. Antimitochondrial antibody heterogeneity and the xenobiotic etiology of primary biliary cirrhosis. Hepatology. 2013;57(4):1498-508

15. Naiyanetr P, Butler JD, Meng L, et al. Electrophile-modified lipoic derivatives of PDC-E2 elicits anti-mitochondrial antibody reactivity. J Autoimmun. 2011:37(3):209-16.

16. Ala A, Stanca CM, Bu-Ghanim M, et al. Increased prevalence of primary biliary cirrhosis near Superfund toxic waste sites. Hepatology. 2006;43(3): 525-31

17. Lleo A, Selmi C, Invernizzi P, et al. Apotopes and the biliary specificity of primary biliary cirrhosis. Hepatology. 2009;49(3):871-79.

18. Locke GR, Therneau TM, Ludwig J, Dickson ER, Lindor KD. Time course of histological progression in primary biliary cirrhosis. Hepatology. 1996;23(1):52-56

19. Ludwig J, Dickson ER, McDonald GS. Staging of chronic nonsuppurative destructive cholangitis (syndrome of primary biliary cirrhosis). Virchows Arch A Pathol Anat Histol. 1978;379(2):103-12.

20. Raczynska J, Habior A, Paczek L, Foroncewicz B, Pawelas A, Mucha K. Primary biliary cirrhosis in the era of liver transplantation. Ann Transplant. 2014;19(1):488-93. 
21. Bentley TS, Hanson SG. 2014 U.S. organ and tissue transplant cost estimates. Milliman Research Report. December 2014. Available at: http://www.milliman.com/uploadedFiles/insight/Research/healthrr/1938HDP_20141230.pdf. Accessed September 8, 2016.

22. Stanca CM, Bach N, Krause C, et al. Evaluation of fatigue in U.S. patients with primary biliary cirrhosis. Am J Gastroenterol. 2005;100(5):1104-09.

23. Goldblatt J, Taylor PJ, Lipman T, et al. The true impact of fatigue in primary biliary cirrhosis: a population study. Gastroenterology. 2002;122(5):1235-41.

24. Björnsson E, Simren M, Olsson R, Chapman RW. Fatigue is not a specific symptom in patients with primary biliary cirrhosis. Eur J Gastroenterol Hepatol. 2005;17(3):351-57.

25. URSO 250 (ursodiol) tablets, for oral use. Aptalis Pharma U.S. June 2013. Available at: http://www.accessdata.fda.gov/drugsatfda_docs/ label/2013/020675s022lbl.pdf. Accessed September 5, 2016.

26. Heathcote EJ, Cauch-Dudek K, Walker V, et al. The Canadian multicenter double-blind randomized controlled trial of ursodeoxycholic acid in primary biliary cirrhosis. Hepatology. 1994;19(5):1149-56.

27. Combes B, Carithers RL, Maddrey W, et al. A randomized, double-blind, placebo-controlled trial of ursodeoxycholic acid in primary biliary cirrhosis. Hepatology. 1995;22(3):759-66.

28. Poupon RE, Poupon R, Balkau B. Ursodiol for the long-term treatment of primary biliary cirrhosis. The UDCA-PBC Study Group. N Engl J Med. 1994:330(19):1342-47.

29. Parés A, Caballeria L, Rodes J, et al. Long-term effects of ursodeoxycholic acid in primary biliary cirrhosis results of a double-blind controlled multicentric trial. J Hepatol. 2000;32(4):561-66.

30. Parés A, Caballería L, Rodés J. Excellent long-term survival in patients with primary biliary cirrhosis and biochemical response to ursodeoxycholic acid. Gastroenterology. 2006;130(3):715-20.
31. Zhang Y, Chen K, Dai W, et al. Combination therapy of bezafibrate and ursodeoxycholic acid for primary biliary cirrhosis: a meta-analysis. Hepatol Res. 2015;45(1):48-58.

32. Grigorian AY, Mardini HE, Corpechot C, Poupon R, Levy C. Fenofibrate is effective adjunctive therapy in the treatment of primary biliary cirrhosis: a meta-analysis. Clin Res Hepatol Gastroenterol. 2015;39(3):296-306.

33. Rautiainen H, Kärkkäinen P, Karvonen AL, et al. Budesonide combined with UDCA to improve liver histology in primary biliary cirrhosis: a threeyear randomized trial. Hepatology. 2005;41(4):747-52.

34. Angulo P, Jorgensen RA, Keach JC, Dickson ER, Smith C, Lindor KD. Oral budesonide in the treatment of patients with primary biliary cirrhosis with a suboptimal response to ursodeoxycholic acid. Hepatology. 2000;31(2):318-23.

35. Leuschner M, Maier KP, Schlichting J, et al. Oral budesonide and ursodeoxycholic acid for treatment of primary biliary cirrhosis: results of a prospective double-blind trial. Gastroenterology. 1999;117(4):918-25.

36. Nevens F, Andreone P, Mazzella G, et al. The first primary biliary cirrhosis (PBC) phase 3 trial in two decades-an international study of the FXR agonist obeticholic acid in PBC patients. J Hepatol. 2014;60(1 Suppl):S525-26. [Abstract O168].

37. OCALIVA (obeticholic acid) tablets, for oral use. Intercept Pharmaceuticals. May 2016. Available at: https://ocaliva.com/ocaliva_pi.pdf. Accessed September 5, 2016.

38. Centers for Medicare \& Medicaid Services. Medicare Part D specialty tier. April 7, 2015. Available at: https://www.cms.gov/Medicare/PrescriptionDrug-Coverage/PrescriptionDrugCovGenIn/Downloads/CY-2016-SpecialtyTier-Methodology.pdf. Accessed September 5, 2016.

39. Calkin AC, Tontonoz P. Transcriptional integration of metabolism by the nuclear sterol-activated receptors LXR and FXR. Nat Rev Mol Cell Biol. 2012;13(4):213-24. 


\section{Posttest Questions}

1. Primary biliary cholangitis ( $\mathrm{PBC}$ ), formerly known as primary biliary cirrhosis, is best classified as which of the following?
a. Common liver disease
b. Rare liver disease
c. Genetic liver disease
d. Autoimmune liver disease
e. Both (b) and (d)

2. Diagnosis of $\mathrm{PBC}$ requires the presence of which of the following criteria?
a. Persistent elevation of serum alkaline phosphatase
b. Presence of antimitochondrial antibodies
c. Liver biopsy consistent with PBC
d. Two of the above criteria
e. All 3 criteria

3. $\mathrm{PBC}$ is most prevalent in which of the following populations?
a. Women
b. Men
c. Children ( $<18$ years)
d. Elderly ( $\geq 75$ years)

4. Which of the following is a common symptom of $\mathrm{PBC}$ ?
a. Nausea
b. Pruritus
c. Fatigue
d. Both (a) and (b)
e. Both (b) and (c)

5. Prior to the introduction of efficacious therapy, what proportion of patients with stage I PBC at baseline remained at stage I after 4 years in a 1996 study?
a. $96 \%$
b. $42 \%$
c. $18 \%$
d. $3 \%$

6. Which of the following procedures could be avoided with appropriate treatment of PBC?
a. Liver transplantation
b. Dialysis
c. Red blood cell transfusion
d. Embolization therapy

7. Which of the following therapies has received FDA approval for the treatment of PBC?
a. Bezafibrate
b. Ursodiol (UDCA)
c. Budesonide
d. None of the above 
8. Which of the following is part of the Toronto criterion for defining response to UDCA?
a. Bilirubin level $\leq 2 \times$ upper limit of normal (ULN)
b. Alkaline phosphatase level $<1.67 \times \mathrm{ULN}$
c. High-density lipoprotein (HDL) level $\geq 60 \mathrm{mg}$ per $\mathrm{dL}$
d. Aspartate aminotransferase level $\leq 5 \times \mathrm{ULN}$

9. Which of the following patient subgroups is less likely to respond to treatment with UDCA?
a. Women diagnosed at an earlier age
b. Patients in earlier stages of the disease
c. Older women
d. Patients with normal HDL levels

10. Which of the following targets has recently generated considerable interest in PBC in terms of bile acid synthesis and its regulation?
a. Retinoic acid receptor
b. Glucocorticoid receptor
c. Farnesoid X receptor
d. Estrogen receptor

11. Obeticholic acid (OCA) met response criteria in a statistically greater proportion of PBC patients with an incomplete response or who were intolerant to UDCA compared with placebo in a phase 3 trial at which of the following dose levels?
a. $5 \mathrm{mg}$ daily titrated to $10 \mathrm{mg}$ daily at 6 months
b. $10 \mathrm{mg}$ daily
c. $15 \mathrm{mg}$ daily
d. Both (a) and (b)
e. Both (c) and (d)

12. What proportion of patients in the OCA $5 \mathrm{mg}$ titration group of the POISE trial discontinued treatment due to pruritus?
a. $>50 \%$
b. $25 \%$
c. $15 \%$
d. $1 \%$

\section{Additional Questions: Program Evaluation}

13. Was this activity objective, balanced, and free from bias?
a. Yes
b. No (If No, why?

14. Do you have any other comments on this program? (optional)

a. 


\section{Supplement}

